\title{
Research on Supporting Method for High Stressed Soft Rock Roadway in Gentle Dipping Strata of Red Shale
}

\author{
Chunde Ma ${ }^{1,2}$, Jiaqing Xu ${ }^{1, * \mathbb{D}}$, Guanshuang Tan ${ }^{1}$, Weibin Xie ${ }^{1}$ and Zhihai Lv ${ }^{1}$ \\ 1 School of Resources and Safety Engineering, Central South University, Changsha 410083, China; \\ cdma@csu.edu.cn (C.M.); tanguanshuang@csu.edu.cn (G.T.); weibin@csu.edu.cn (W.X.); \\ lvzhihai@csu.edu.cn (Z.L.) \\ 2 Advanced Research Center, Central South University, Changsha 410083, China \\ * Correspondence: xu1001@csu.edu.cn; Tel.: +86-15904920851
}

Citation: Ma, C.; Xu, J.; Tan, G.; Xie, W.; Lv, Z. Research on Supporting Method for High Stressed Soft Rock Roadway in Gentle Dipping Strata of Red Shale. Minerals 2021, 11, 423. https://doi.org/10.3390/min11040423

Academic Editor: Abbas Taheri

Received: 15 March 2021

Accepted: 13 April 2021

Published: 16 April 2021

Publisher's Note: MDPI stays neutral with regard to jurisdictional claims in published maps and institutional affiliations.

Copyright: (c) 2021 by the authors. Licensee MDPI, Basel, Switzerland. This article is an open access article distributed under the terms and conditions of the Creative Commons Attribution (CC BY) license (https:// creativecommons.org/licenses/by/ $4.0 /)$.

\begin{abstract}
Red shale is widely distributed among the deep mine areas of Kaiyang Phosphate Mine, which is the biggest underground phosphate mine of China. Because of the effect of various factors, such as high stress, ground water and so on, trackless transport roadways in deep mine areas were difficult to effectively support for a long time by using traditional supporting design methods. To deal with this problem, some innovative works were carried out in this paper. First, mineral composition and microstructure, anisotropic, hydraulic mechanical properties and other mechanical parameters of red shale were tested in a laboratory to reveal its deformation and failure characteristics from the aspect of lithology. Then, some numerical simulation about the failure process of the roadways in layered red shale strata was implemented to investigate the change regulation of stress and strain in the surrounding rock, according to the real rock mechanical parameters and in-situ stress data. Therefore, based on the composite failure law and existing support problems of red shale roadways, some effective methods and techniques were adopted, especially a kind of new wave-type bolt that was used to relieve rock expansion and plastic energy to prevent concentration of stress and excess deformation. The field experiment shows the superiorities in new techniques have been verified and successfully applied to safeguard roadway stability.
\end{abstract}

Keywords: high stressed soft rock roadway; wave-type bolt; support technology

\section{Introduction}

As the mining depth increases, the in-situ stress increases rapidly, the original support technology and measures are invalid, the roadway repair rate is high and there are frequent roof falls, slabs, bottom heaves, etc. [1-3] after permanent roadway support, which requires multiple maintenances. With reinforcement, maintenance workload and high support cost have a serious impact on the normal and safe mining of the mine in Kaiyang Phosphate Mine. The large deformation of the roadway severely restricts the production of soft rock mines [4-6]. Roadway support is a crucial step in the mining process, and it is also the direction that many scholars have been studying [7-9]. The traditional support method of bolts, cables and steel supports do not distinguish between soft and hard rock. At the same time, the current internationally popular New Austrian Tunnelling Method (NATM) does not clearly answer the question of what the support object is $[10,11]$. Therefore, it is particularly critical to ensure the safety of roadways in deep inclined rock formations.

Before supporting, it is necessary to clarify the failure mechanism of surrounding rock. The failure mechanism of the surrounding rock of roadway has been extensively investigated in recent years. Wu et al. [12] studied the deformation mechanism of soft rock roadway through in-situ monitoring technology, and the study pointed out that high ground pressure and low rock strength are the main factors that cause large roadway deformation. Li et al. [13] used an exploratory physical model, numerical simulation and field measurements to evaluate the deformation and failure modes of soft rock roadways. 
He et al. [14] believe that deep underground support engineering should mainly consider how to counteract dynamic impact and retain the suitable rock mass deformation. Li et al. [15] discovered that the surrounding rock stress gradually decreases, meanwhile the deformation and failure mainly occur to the center of the roadway roof. Yang et al. [16] conducted a study on the failure mechanism of deep soft rock roadways in Xin'an Coal Mine, Gansu, China and found that the failure was first caused by high deviator stress caused by excavation, and then the damage expanded upon the deep part. At the same time, various damage phenomena in the shallow part were analyzed as tensile. Guo et al. [17] observed that the deformation of the soft rock roadway started from the roof and then led to the destruction of the entire support system. They believed that the cause of the failure was the uncoupling of the support mechanism and the surrounding rock. In addition, many scholars have discovered different failure mechanisms of surrounding rocks and analyzed the reasons for a targeted manner [18-20].

In response to the above problems, researchers have developed some theories and techniques for soft rock support. In order to solve the serious initial deformation of the soft rock roadway in Xiaokang Coal Mine, Wang et al. [21] designed a set of circular fully enclosed combined support systems, including high-strength prestressed bolts, a "W"-type strong anchor cable and U-shaped yielding steel. Chang et al. [22] used hydraulic expansion bolts to solve the problem of the floor heave of the soft rock roadway and overcome the adverse effects of residual rock powder in the bolt holes. Wang et al. [23] developed a confined concrete support system, using high-strength arch supports to ensure safe mining in Liangjia Coal Mine. Shreedharan et al. [24] used discrete element simulation software to analyze the stability of tunnels with different cross-sections under high stress, which provided a reference for the shape and support of the tunnel. Yu et al. [25] investigated a combined support methodology and optimized the support parameters by analysis of the field structure of weak surrounding rock to ensure the safety of the roadway. Although scholars work together to attempt to ensure safe production of deep stopes, there are still hidden safety hazards in some soft roadways. The support technique for highly stressed soft rock roadways still needs further development and study [26,27], especially when the roadway lays in a gently dipped layered soft rock mass with the typical bedding structure, which is a challenge to the control of soft rock with great deformation failure and rheological property [28].

In this paper, the failure mechanisms of the typical soft rock (red shale) have been investigated by testing for mineral composition and microstructure, anisotropic and hydraulic mechanical properties and ground stress and analyzing of evaluation on existing support and numerical simulation on layered strata. Based on the failure mechanism, the approved version of the shotcrete rock bolt mesh technique is proposed to new-designed wave-type bolt layout installed at different angles for controlling the bedding structure. Besides, other helpful engineering suggestions were proposed. Finally, in-site industrial experiments results have validated the new support technique's reasonableness.

\section{Mechanical Properties of Red Shale}

In Kaiyang Phosphate Mine, most of the main development roadways are arranged in the footwall (red shale rock strata), which presents an inclination angle close to 31 degrees as shown in Figure 1. The effect of rock mechanical properties on roadway stability is obvious, and the mineral components of rock have a decisive influence on rock mechanical properties. To investigate the failure mechanisms of the deep red shale rock roadways, a series of laboratory tests have been completed to learn the special physical and mechanical characteristics of red shale, including mineral composition and microstructure test, hydraulic mechanical properties, creep characteristic and anisotropic test.

\subsection{Mineral Composition and Microstructure Test}

The red shale sample was taken from a new heading face of main haulage roadway in No.640 middle level in Kaiyang Phosphate Mine, then cut into slices and tested using 
a microscope. The main mineral compositions were figured out as shown in Table 1: its components of debris are quartz, orthoclase, sericite, muscovite and little zircon. And the interstitial materials are composed of calcite, quartz, sericite, clay-type mud and ferruginous cementation. Clay-type mud accounted for $35 \%$ of mineral composition.

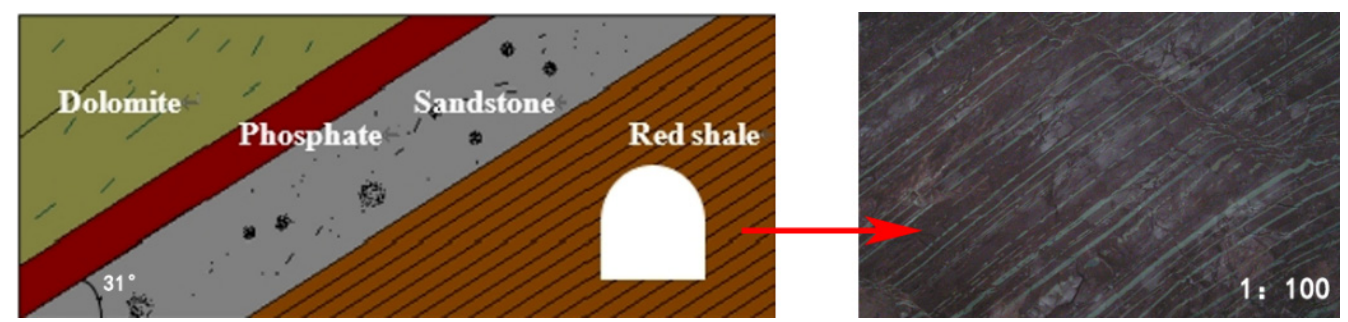

Figure 1. The red shale inclined bedding structure around roadway cross section.

Table 1. The main mineral composition and its content of red shale.

\begin{tabular}{cc}
\hline Mineral Name & Content $\%$ \\
\hline Clay-type mud & 35 \\
Quartz & 20 \\
Orthoclase & 15 \\
Sericite & 12 \\
Muscovite & 8 \\
Calcite & 5 \\
Ferruginous cementation & 5 \\
Zircon & Little \\
\hline
\end{tabular}

The red shale was observed with a polarizing microscope, and the result is shown in Figure 2. A muddy layer distributed among the main part of the rock can be observed in the slice's border, which is made up of $85 \%$ interstitial material and $15 \%$ chippings. Based on the microstructure graph under polarizing filters and mineral composition, red shale can be classified as amaranth shale with pelitic and aleuritic textures and bedding structure.
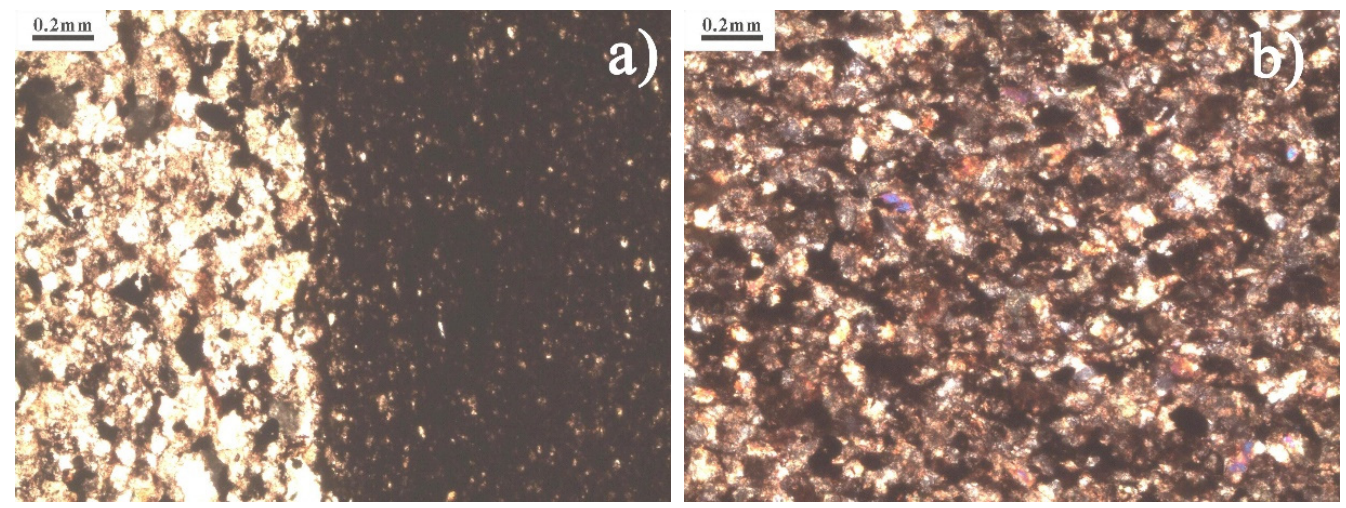

Figure 2. Red shale's polarizing microscope graph. Note: (a) plane polarized light; (b) perpendicular polarized light.

\subsection{Hydraulic Mechanical Properties Test}

From the above investigation into mineral composition, clay-type mud is the main ingredient of red shale. Therefore, groundwater and humid air have a great impact on rock strength and roadway stability. In order to clarify the failure mechanism of roadways arranged in red shale, it is necessary to conduct detailed research on various engineering mechanical properties of this rock. Uniaxial compressive strength experiments, rock expansion experiments and creep experiments under the influence of water were set up to investigate its hydraulic mechanical properties. Rock samples all came from the same 
drill hole. As shown in Figure 3, the dip angle of all rock samples was completely the same: about $31^{\circ}$ perpendicular to loading direction. The length of the drill hole was more than $50 \mathrm{~m}$ so that the effect of blast vibration and other factors from mining could be neglected. According to the standard testing method of ISRM (International Society for Rock Mechanics), rock mass was processed to standard rock samples with an L/D ratio of 2 with an average diameter of $50 \mathrm{~mm}$ and remaining average natural water content less than $1 \%$ sealed.

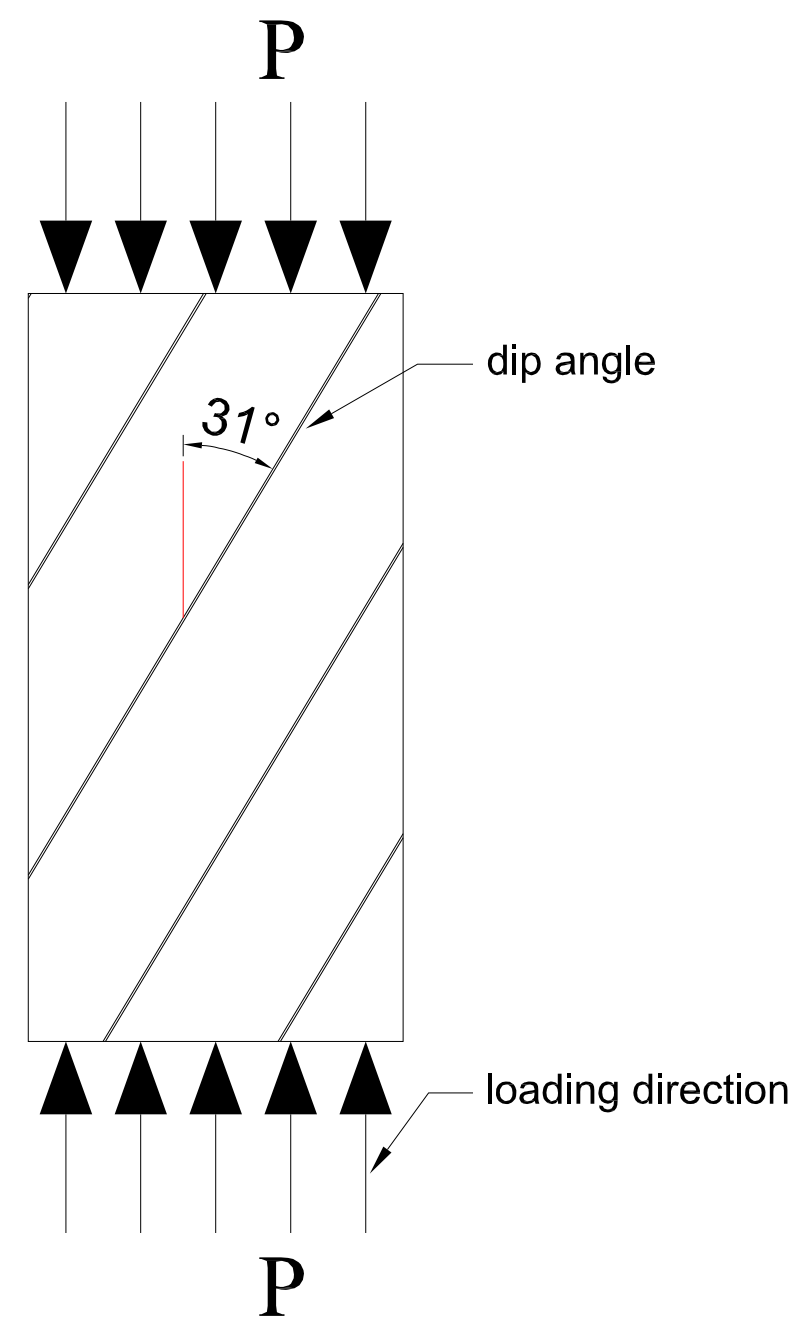

Figure 3. Schematic diagram of red shale joints and the orientation of the load.

\subsubsection{Uniaxial Compressive Strength Experiment}

The rock samples soaked for different times or drying on drying box had their uniaxial compressive strength tested on the Instron 1342 testing machine (Instron, UK). The loading pattern was set to displacement control with the rate of $0.3 \mathrm{~mm} / \mathrm{min}$. Three samples were selected for the uniaxial compression test for each immersion time. The uniaxial compressive strength of the rock samples with the same immersion time was averaged. All results are shown in Figure 4. When immersion time was less than two hours, the uniaxial compressive strength of the rock samples sharply decreased from $22.22 \mathrm{MPa}$ to 7.94 MPa. The uniaxial compressive strength of rock samples soaking for over $24 \mathrm{~h}$ was only 5.04 MPa, equivalent to a quarter of a rock sample's strength in natural state. When immersion time exceeded $72 \mathrm{~h}$, water-saturated rock samples partly disintegrated before loading and the uniaxial compressive strength is the lowest one and only about $1.56 \mathrm{MPa}$. 


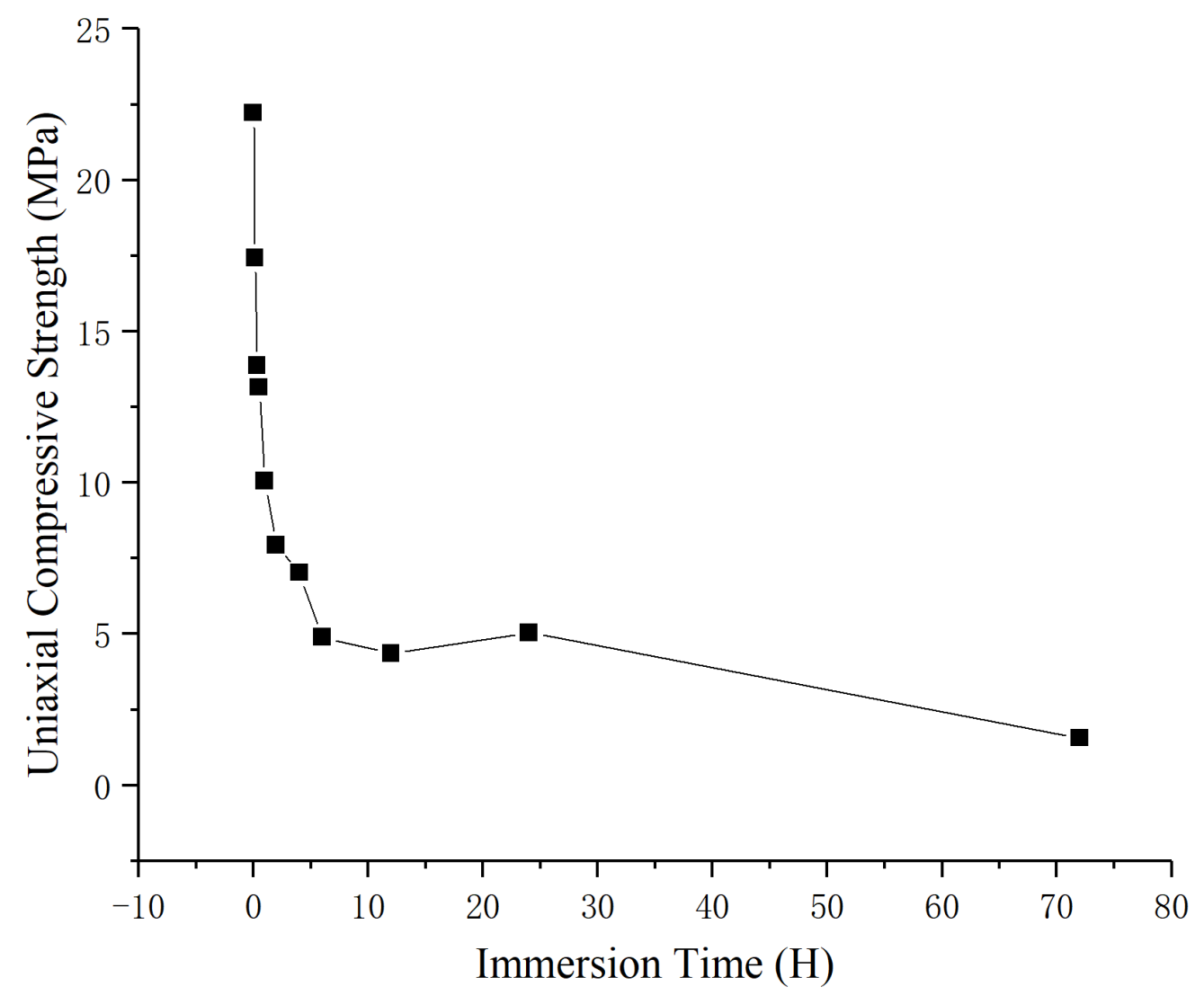

Figure 4. The relation of uniaxial compressive strength and immersion time.

\subsubsection{Expansion Experiment}

The rock expansion experiment under water swelling was been implemented by using a digital rock free swelling ratio test device that is made up of a height adjustable metal support, three high-precision displacement sensors and a data collection system. Its measure precision can reach $0.001 \mathrm{~mm}$ with real-time gathering data onto frequency of $100 \mathrm{~Hz}$. Lab measures scene is shown as Figure 5. As shown in Figure 6, in the first hour, the axial and lateral displacements increased rapidly at the same time. One hour later, the lateral displacement exceeded the axial displacement and increased rapidly in the next six hours, while the axial displacement reduced the growth rate at this time to a slow increase, and then the lateral displacement growth rates decreased and stabilized. The axial displacement kept increasing slowly from the second hour to the end of the experiment. It is worth mentioning that the sample disintegrated at the twenty-sixth hour of the experiment, resulting in a sudden increase in displacement, but then the displacement of the sample continued to stabilize, and finally the axial and lateral displacement reached $0.15 \mathrm{~mm}$ and $0.13 \mathrm{~mm}$, respectively. It can be clearly seen that the axial and lateral deformation of red shale increased significantly with the increase of water immersion time, and was most significant in the first two hours.

\subsubsection{Creep Characteristic Test}

Red shale creep experiments were implemented by an Instron test machine. Most of the loading condition was respectively set as $10 \%, 20 \%, 30 \%, 50 \%, 70 \%$ and $80 \%$ of the uniaxial compressive strength. Rock samples were in natural moisture state except that one rock sample of loading with 50\% UCS (Uniaxial Compressive Strength) in water saturated state. As shown in Figure 7, red shale's displacement is increased while load raising so that creep behavior is clear. When the loading reached $80 \%$ for the rock sample, macroscopic failure was obviously happening. It can be concluded that red shale's creep rupture strength is only about $70 \%-80 \%$ of its uniaxial compression strength in its natural moisture state. 
Water also affects red shale's creep rupture strength a lot. Red shale's creep displacement in water saturated state is apparently larger than natural moisture states. Meanwhile, its macroscopic failure can be seen after $3500 \mathrm{~s}$, so red shale's creep rupture strength also declined a lot in its water saturated state. When loading is less than the critical load of softening, red shale is within stable deformation state. Red shale's plastic deformation will happen to the critical load of softening. As learned from the creep experiment, red shale's critical load of softening is only about $70-80 \%$ of uniaxial compression strength in natural moisture state and $30-50 \%$ of uniaxial compression strength in water saturated state.

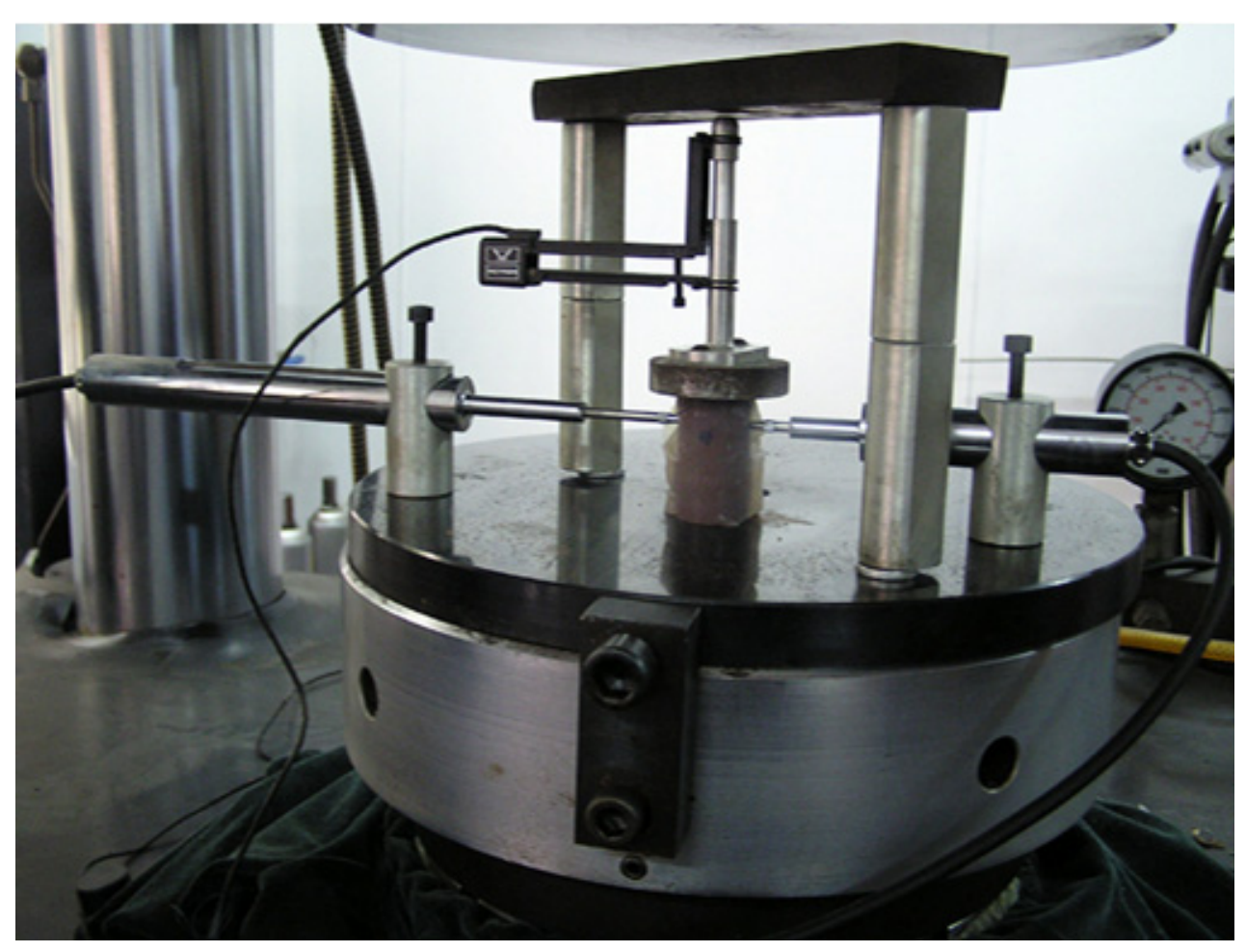

Figure 5. Digital measure device for rock free swelling ratio.

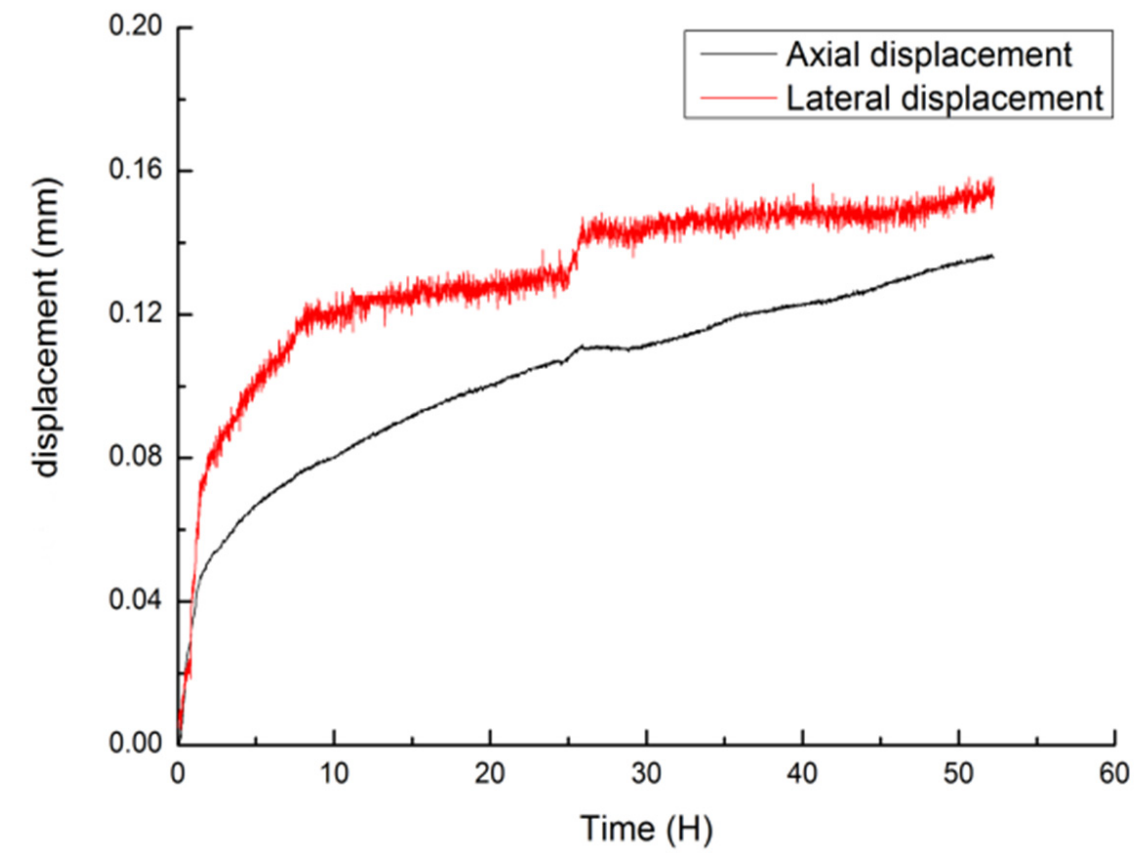

Figure 6. Red shale's expansion displacement in vertical and lateral direction within sixty hours. 


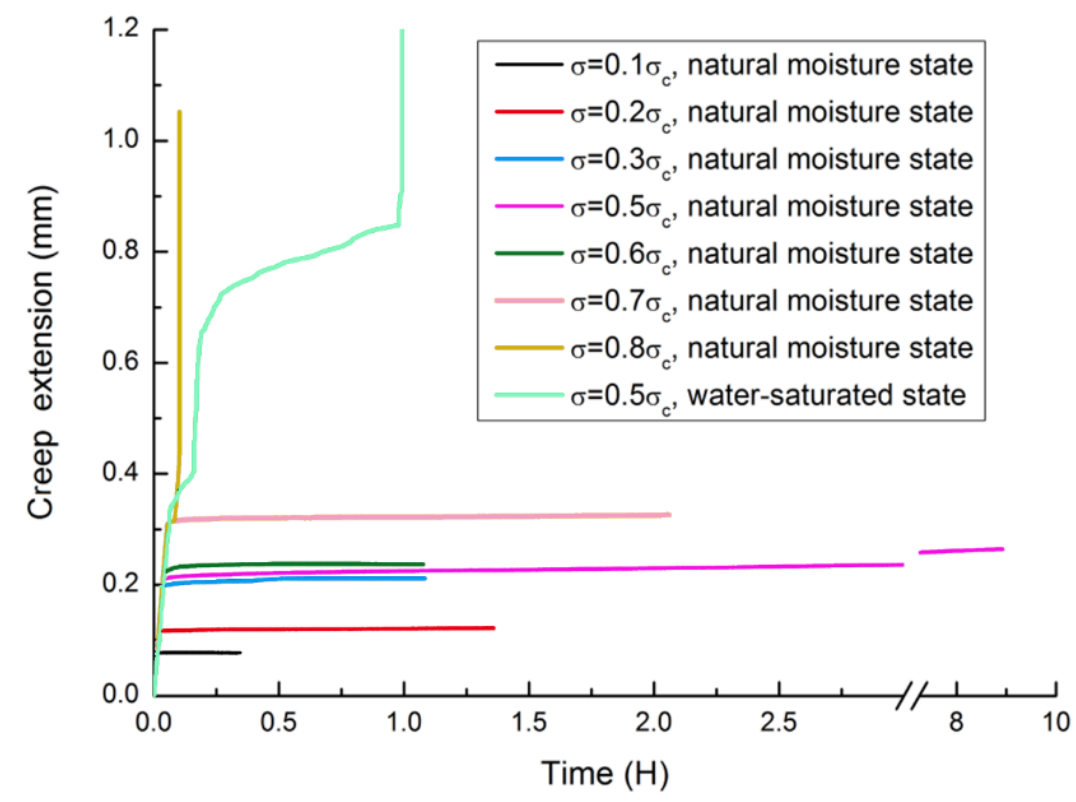

Figure 7. Red shale's creep experiments result in different constant loading and water effect.

\subsection{Anisotropic Mechanical Properties Test}

The bedding structure can affect structure stability a lot [29]. By the means of microstructure analysis and appearance morphology survey, it can be found that red shale is apparently thin layered bedding structure spacing from micron to millimeter. Therefore, the anisotropic mechanical properties have been investigated in this section. Rock mass taken from field was processed into standard rock samples of different states with parallel, vertical and oblique bedding (i.e., splitting into different dip angles respectively of about $0^{\circ}$, $30^{\circ}, 45^{\circ}, 60^{\circ}$ and $90^{\circ}$ ). Then, the standard uniaxial compressive, tensile and shear strength tests were carried out on the Instron 1342 electro-hydraulic servo controlling material testing machine. As the results show in Figure 8, red shale has typical thin bedding structure and apparently anisotropic mechanical feature. Red shale's mechanical properties are different as with different dip angles of bedding structure.

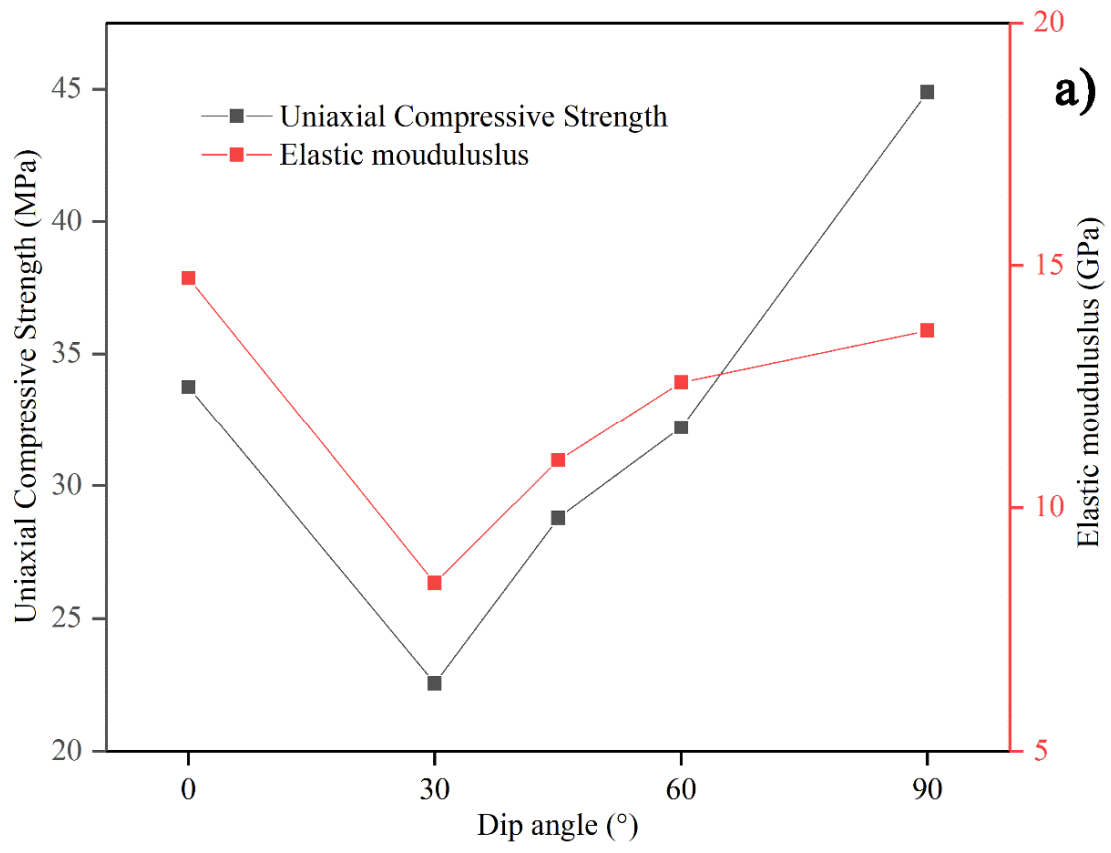

Figure 8. Cont. 


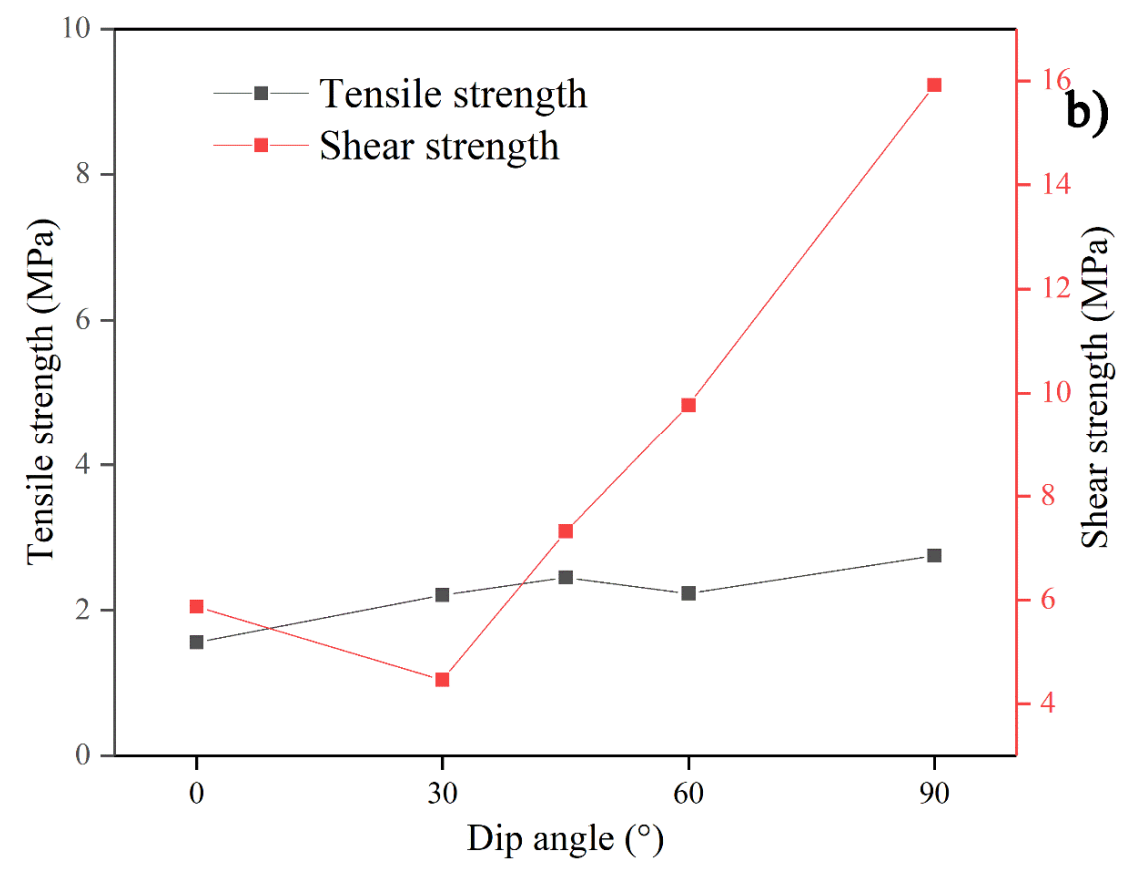

Figure 8. The graphs of red shale's mechanical properties in different dip angles. Note: (a) Uniaxial Compressive Strength and Elastic modulus in different dip angles; (b) Tensile strength and Shear strength in different dip angles.

The uniaxial compressive, tensile and shear strength are highest in vertical bedding. The strength index is the last one while the dip angle is $30^{\circ}$. Elastic modulus is the highest in parallel bedding. Shear strength of sample rock in parallel bedding is obviously lower in comparison to vertical beddings.

\section{Validation of Numerical Simulation on Layered Strata}

\subsection{Numerical Model}

In order to determine the displacement field change and the distribution law of the plastic zone, the 3DEC numerical analysis software (4.10) was used to simulate and analyze the main haulage roadway with 640 levels in the deep. In order to ensure the authenticity of the data of the simulation experiment, before the numerical simulation experiment, the in-situ stress measurement was carried out by borehole strain over-coring method, and the distribution and change law of the three-dimensional in-situ stress field in Kaiyang Phosphate Mine were obtained. The numerical simulation model size was $200 \times 200 \times 200 \mathrm{~m}$, and the dip angle of red shale was $31^{\circ}$. The surrounding rock is red shale, and different colors were used in the model to reflect the dip angle. The model is shown in Figure 9. The Drucker-Prager criterion was adopted in the simulation. The left and right, front and back boundaries and bottom boundary of the model adopted fixed boundary displacements. A vertical compressive stress of 13.2MPa was applied to the upper surface of the model. The calculated area size was $15 \mathrm{~m} \times 15 \mathrm{~m} \times 15 \mathrm{~m}$. The model calculation parameters are shown in Table 2.

\subsection{Analysis of Numerical Simulation}

The contour diagrams of stress and displacement in the vertical and horizontal directions have been saved as Figure 10. Numerical simulation results have verified some phenomenon observed from field detection. After roadway excavation, the roadway displacement and effect zone around bedding direction are larger than other directions, and the floor deformation is the largest in other parts of the cross section.

Learned from Figure 10a, there are stress concentrations in the sides and roof corners approaching the roadway's surface after excavation. The maximum value of tensile stress is about $0.38 \mathrm{MPa}$. For roadway stability, the presence of tensile stress concentration in 
this area is very bad. Learned from Figure $10 \mathrm{~b}$ the stress concentration region in a vertical direction can be classed as an X-type shape on the axial line of roadway. A tensile stress of about $0.30 \mathrm{MPa}$ is generated at the top and bottom plates, and the range of tensile stress concentration almost covers the entire top and bottom plates. Affected by bedding structure, the vertical stress is not completely symmetrically distributed on the sides of roadway. The effect range perpendicular to the bedding direction is larger than in other directions.

Learned from Figure 10c, rock strata's bedding direction apparently affects the deformation distribution in horizontal direction. The displacement on the sides and floor of the roadway is larger than in other parts. And the displacement on the left side is larger than the other sides. The high stress squeezes roadway sides with the free face. From Figure 10d in vertical direction, most of the deformation is from floor heave besides roof collapse. The phenomenon observed from the field also verified the above analysis.

After roadway excavation without immediate support, the plastic zones tend to expand and break, and the broken rock's deformation is larger than the rock mass in the plastic zone. The floor heave is the main part of surrounding rock deformation, which exceeds other parts. The bedding direction affects ground stress distribution and roadway's displacement a lot. Roadway's displacement along the bedding direction is so large that the plastic zone is small. Vertical to the bedding direction, the above-mentioned parameters are just opposite, so it is easy for them to cause support failure. Therefore, it is better that the water ditch is set on the right bottom corner and strengthening support on the left shoulder corner. The deep in-suit stress concentrates on the bottom corners, which is going to enlarge and squeeze the roadway and lead to large floor heaves so that the roadway floor's support has to be reinforced.

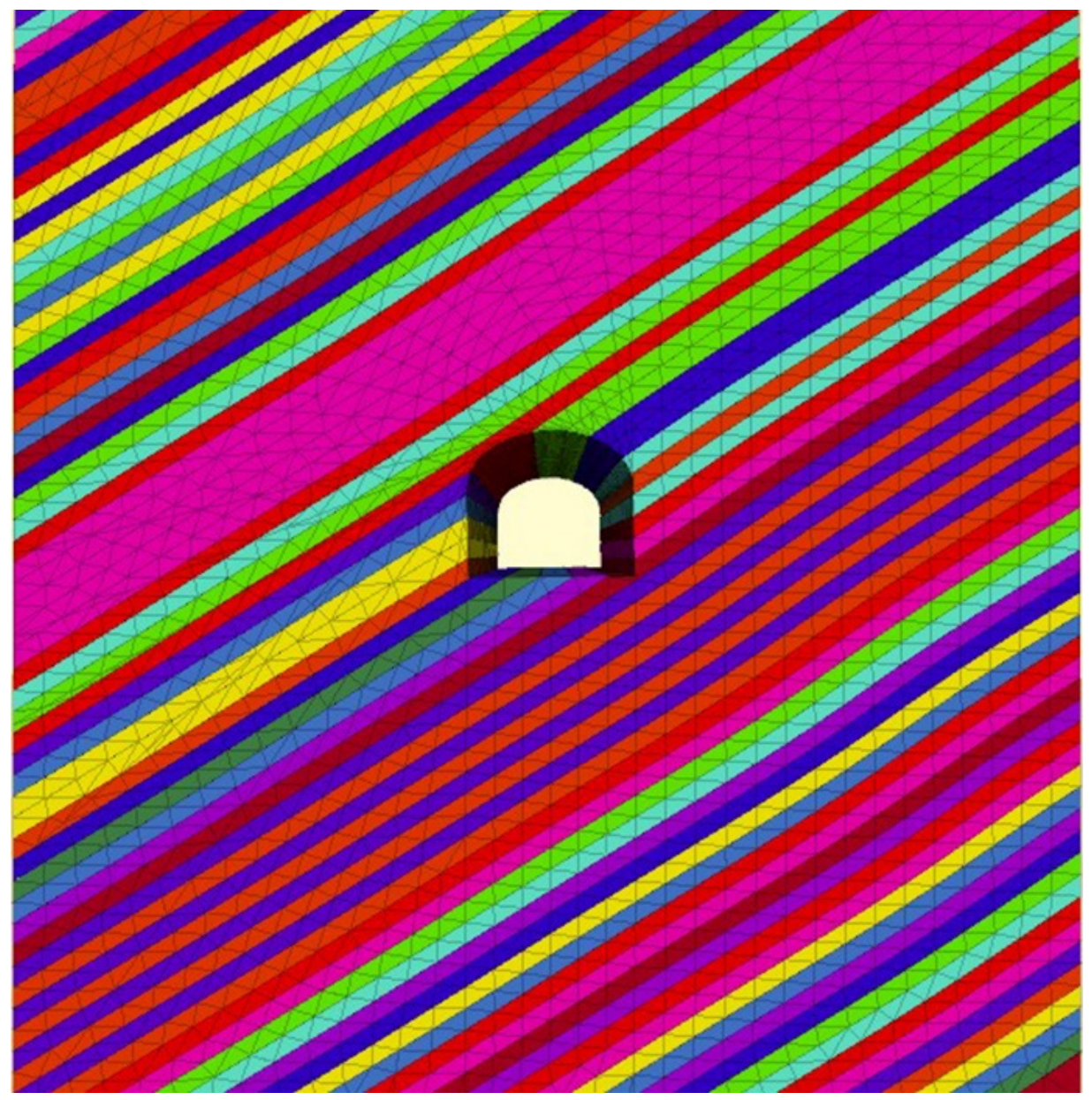

Figure 9. The calculation model. 
Table 2. The model calculation parameters.

\begin{tabular}{ccccccc}
\hline $\begin{array}{c}\text { Normal Stiffness } \\
(\mathrm{GPa} / \mathrm{m})\end{array}$ & $\begin{array}{c}\text { Shear Stiffness } \\
(\mathrm{GPa} / \mathbf{M})\end{array}$ & Cohesion/MPa & $\begin{array}{c}\text { Internal Friction } \\
\left.\text { Angle/( }{ }^{\circ}\right)\end{array}$ & $\begin{array}{c}\text { Tensile } \\
\text { Strength/MPa }\end{array}$ & $\begin{array}{c}\text { Elastic Modulus } \\
(\mathrm{GPa})\end{array}$ & $\begin{array}{c}\text { Poisson's } \\
\text { Ratio }\end{array}$ \\
\hline 5.2 & 2.63 & 1.05 & $30^{\circ}$ & 1.5 & 9 & 0.24 \\
\hline
\end{tabular}
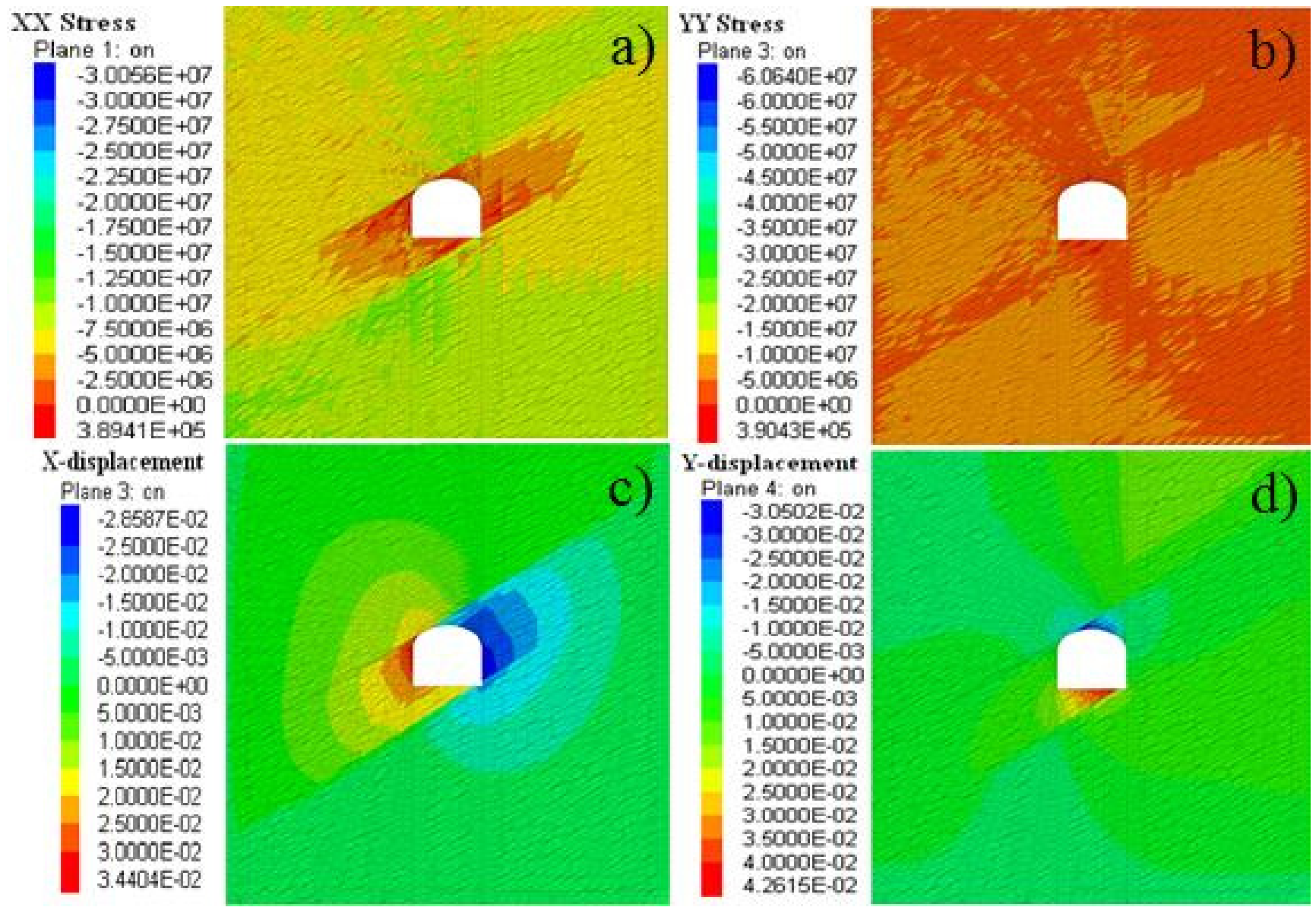

Figure 10. The stress contour diagrams and displacement contour diagrams in the vertical and horizontal direction. Note: (a) Horizontal stress distribution; (b) vertical stress distribution; (c) Horizontal displacement distribution; (d) vertical displacement distribution.

\subsection{Analysis of Numerical Simulation}

Through laboratory analysis and numerical simulation verification, it can be concluded that red shale is not engineered soft rock in the traditional sense. Its uniaxial compressive strengths parallel to and perpendicular to the bedding all exceed $25 \mathrm{MPa}$, and exhibit brittleness under low stress. The deformation is a characteristic of rock, but it will undergo obvious brittle-ductile transformation under high stress conditions and significant plastic deformation will occur, showing obvious engineered soft rock properties, with reduced long-term strength and enhanced rheological characteristics. Because its mineral composition contains clay-like components, it will swell and soften significantly when exposed to water, which significantly deteriorates its engineering mechanical properties. So, red shale deformation characteristics can be drawn as three deformation mechanisms of weathering collapse after water absorption, destruction under high stress and uniformed destruction of bedding structure. After exposure to excavation, red shale is easy to soften, swells with water, and weathering causes its poor performance of debris and interstitial material, then its engineering mechanical behavior and strength quickly weaken. When the stress levels that the roadway sustains exceeds critical softening loading, including tectonic stress, gravity stress, secondary stress adjustment and mining induced influence, plastic 
deformation of red shale sharply increases and softens. The roadway is seriously squeezed by large deformation and rheo-destruction. Under high stress, the layered red shale tends to wrinkle to free face on the roadway floor. It has to consider the influence of bedding direction to the stress level and displacement on surrounding rock. The interaction and influence of the three deformation mechanisms keep the support cost high and affects the normal production of the stope.

\section{New Support Scheme}

With mining depth increasing in the Kaiyang Phosphate Mine area, the ground stress is higher than in shallow parts. The existing bolt-mesh-grouting technique cannot adapt to the high ground stress environment in deep parts. Especially, the deformation features of layered soft rock have not been taken seriously. Original roadways support has not been strengthened to limit nonlinear large deformation. So, there are many roadways destruction phenomenon, like rock collapse, bolt retracting and floor cracks, shown in Figure 11. Some roadways even cannot keep a regular working state and personnel safety. Therefore, we proposed a new support design to meet support requirements in new excavation roadway. In view of red shale compound failure mechanisms analysis, it is reasonable to apply coupled support methods to simplify roadway failure mechanisms. Then, the support scheme for shotcrete rock bolt mesh technique is proposed to new-designed wave-type bolts.
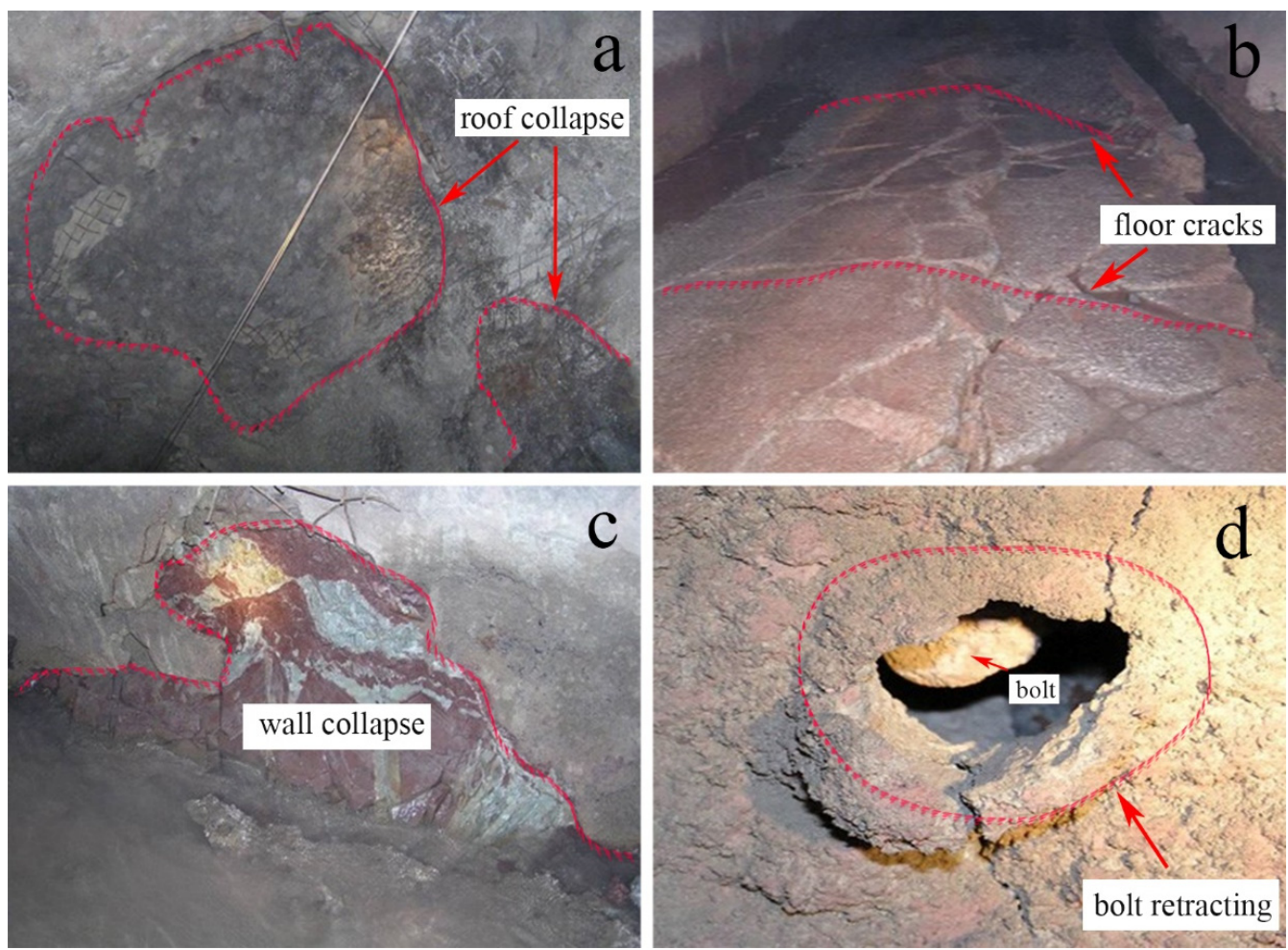

Figure 11. The different roadways failure phenomenon in Kaiyang Phosphate Mine area. Note: (a) roof collapse; (b) floor cracks; (c) wall collapse; (d) bolt retracting.

\subsection{Wave-Type Bolts Support}

Because of surrounding rock compound features of strength weakness and expansion rheology, the existing support technique of shotcrete rock bolt cannot effectively take control of surrounding rock loosening region. Support for soft rock roadways needs to allow the existence of a plastic circle releasing the surrounding rock deformation energy to safeguard rock strength. The support system must provide enough support resistance to limit the plastic circle region and prevent rock collapse. Meanwhile, it should be flexible and easy to adapt to the nonlinear deformation for rock expansion of coupled stress field. 
The deformation energy and support loading can be controlled after several adjustments of stress and strain. Finally, the interaction between the roadway support and surrounding rocks come into being a synergetic bearing system. Therefore, scholars have developed a new bolt and named it energy-absorbing bolt. The traditional energy-absorbing bolt's functions just meet the support materials' requirements about strength and flexibility [29]. Therefore, a new type of bolt is proposed, which has high strength and large deformation ability. As shown in Figures 12 and 13, for accommodating large rock dilations of roadways surrounding rock under high stress, like in Kaiyang mine area, the new energy-absorbing bolt has been created with an anchor section.
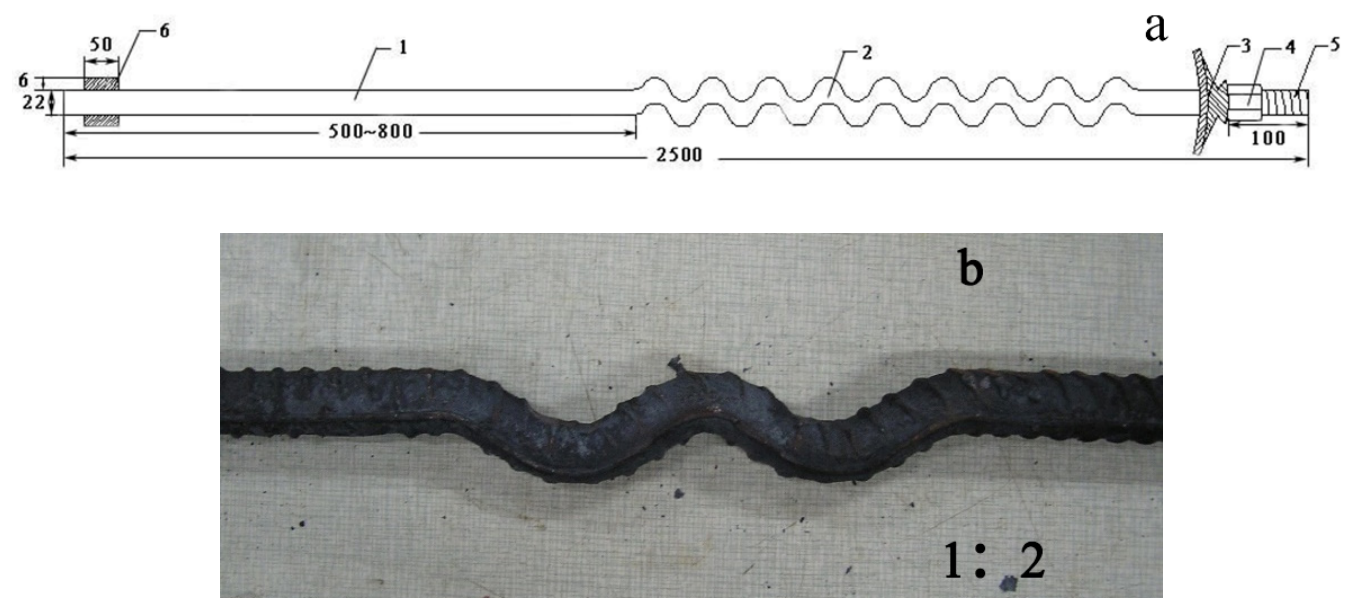

Figure 12. The wave-type bolt's construction diagram. 1-Prolonged anchor section, 2-Sine-wave structure section, 3-Pallet, 4-Fastening nut, 5-Threaded section, 6-Stirring wing. Note: (a) The wave-type bolt; (b) Sine-wave structure section.

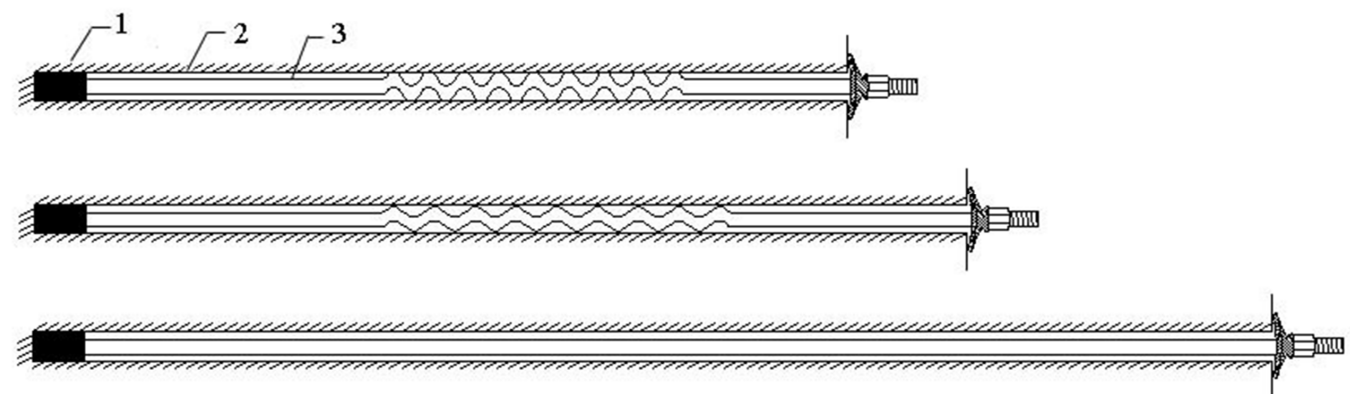

Figure 13. The wave-type bolt's construction diagram. 1-surrounding rock, 2-borehole, 3-wavetype bolt.

The energy-absorbing anchor section is processed into a sine wave shape. Through calculation, the arc length is set to $119.883 \mathrm{~mm}$ and the chord length is set to $113.097 \mathrm{~mm}$, so the maximum elongation is $6.786 \mathrm{~mm}$. When the bolt completely has stretched straight by rock mass, the accumulated deformation can reach $53 \mathrm{~mm}$. The setting of the energyabsorbing section means that the borehole diameter needs to be enlarged. These increments are insignificant compared to the spacing of the anchor rods. In order to avoid water vapor corrosion, the swelling sponge will be used to block the orifice during anchoring. In in-site experiments, the wave-type bolt will not break as its drawing force can reach $150 \mathrm{kN}$. When the deep soft rock needs to relieve plastic energy, the wave-type bolt can coordinate deformation to store huge energy, avoiding rock mass collapse. In key sections of roadway (proof, floor, sides, arch corner and bottom corner), the rigid support transformed into flexible support adopted by the newly designed wave-type bolts layout, as shown in Figure 13.

The wave-type section is a high-strength spiral steel bar processed as sine-wave type by heat-treatment technology. The other components, like pallet, fastening nut and 
threaded section, are completely the same with the straight-rod spiral steel bolt. The stirring wing is two steel reinforcing rods with a length of $50 \mathrm{~mm}$ and diameter of $6 \mathrm{~mm}$ welded on the top of the lengthening anchor section, which enhance the ability of stirring for strengthening resin anchor effect.

The prolonged anchor section at one end is past on the borehole's surface rock. Another end is anchored on surrounding rock by a pallet and fastening nut, which can provide a pre-stress on the anchor rod body. In the high stress state, there is compression deformation for free face from the surrounding soft rock; the reacting force for surrounding rock gradually increases for the wave-type bolt. Then, the eight anchors section begins to gradually stretch and assimilates deformation energy from the surrounding rock. Simultaneously, the wave-type bolt also makes a reacting force to limit rock deformation. When the deformation of surrounding rock is going to increase, there will be a stronger reacting force to the straight-rod for rock squeezing. As the wave-type section relieves much more energy leading to large deformation, the higher reacting force from wave-type bolts is generated to limit deformation from rock mass. After the wave-type section is stretched to be completely straight, the rod body sustains the maximal pressure in surrounding rock like a high-strength rigid bolt. In time and space, the wave-type bolts coordinate the rock mass's deformation so that the internal pressures can be relieved moderately to limit excessive deformation.

\subsection{Bolt-Net-Anchor Coupling Support and Controlling of Sidewalls and Corner}

The full cross-section bolt-net-anchor coupling support is used to strengthen support strength. For bedding structure of the layered red shale and plastic deformation, the moving displacement of layered rock leads to uncoordinated deformation of surrounding rock and support materials in some weak sections and it is easy to lose system stability. Therefore, the long steel bolts and grouting immediately is used to strengthen support in the roof section of the roadway intersection and broken rock strata. For the influence of bedding structure, the stress is asymmetrically distributed over the horizontal direction of the roadway so that the water ditch is set on the right hand for the small horizontal displacement and it is easy to maintain its original shape. The stress concentration on the left arch corner and right bottom corner is serious so the roadway supports need to be strengthened by means of increasing the long steel bolt's amount of left arch corner or reducing the bolts spacing and masonry reinforcement on the right bottom corner. In consideration of the anisotropic mechanical properties, the support design should ensure the maximization of the installation angle of the bolt direction and the bedding orientations to give full play to the strength of the surrounding rock. While the bolt's parallel to bedding, it should readjust the installing angles of bolts on bedding directions.

\subsection{Groundwater Controlling and Secondary Support}

After roadways excavation, metallic net must immediately be laid to increase toughness, then concrete cement sprayed to seal the flat land floor to avoid water erosion weakening rock strength. In the intersection of roadways, the anchor cable for support should be lengthened and the surrounding rock should be pre-grouted in the fracture zone to strengthen before support work. After ground stress redistribution and roadway maintaining stability, the function-losing bolts should be replaced, adapted to secondary intensifying support in key sections and grouted to protect broken rock mass.

\subsection{Support Parameter}

Many successful support cases show that the combined support of anchor net and shotcrete is a common and mature method. By referring to the similar soft rock mine support plan, the anchor rod is still used as the main support. From the previous analysis, it can be seen that because it is perpendicular to the bedding structure, the stress concentration on the left corner and the right bottom corner is more obvious, so the left corner is appropriate. Reducing the bolt spacing and setting the water ditch at the right bottom 
corner is more conducive to roadway support. The row and column spacing of the bolts is $800 \mathrm{~mm} \times 1000 \mathrm{~mm}$. At the same time, wave-type bolts are used at several key points of the roadway to control the deformation of the soft rock roadway. The bottom corners of both sides are made of thick round steel to enhance the support of the bottom plate. The bottom plate is made of poured concrete. The support is enclosed by the ground, and a layer of metal mesh is laid on the ground to increase the toughness. Figure 14 is a sketch of the new roadway support schemes.

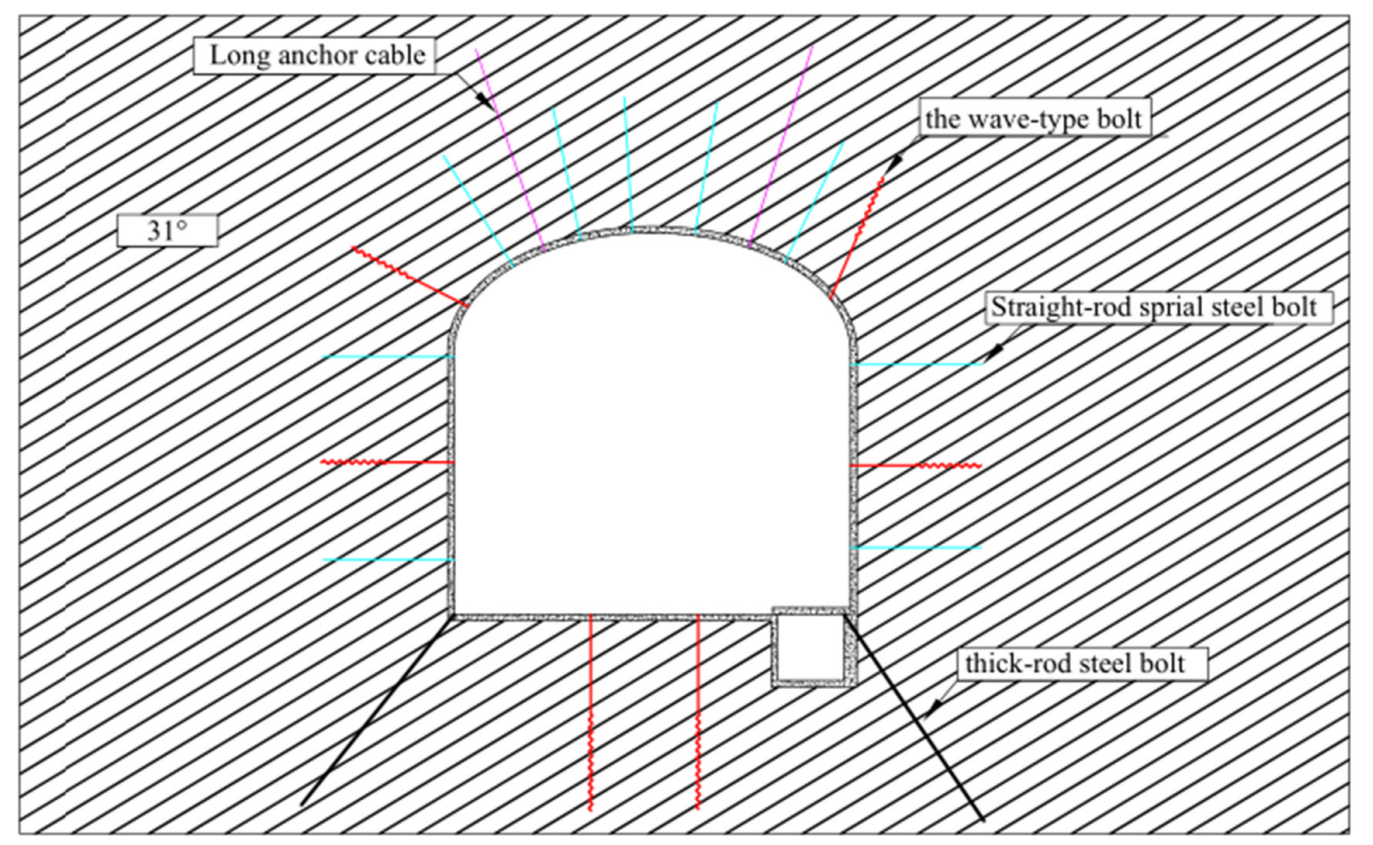

Figure 14. Sketch of the new roadway support schemes.

It should be noted that the supporting method mainly adopts full-section support with bolt and shotcrete net, while strengthening the control of the bottom drum. When constructing the anchor rods at the left bottom corner and the right arch corner, the drill holes of the anchor rods cannot be parallel to the bedding direction. The stress concentration is more obvious at the left arch corner and right bottom corner perpendicular to the bedding direction, and support should be strengthened near these positions. After the excavation of the roadway, the initial spraying and sealing of the floor should be carried out as early as possible, and fiber materials should be added to the concrete to enhance its plasticity. Thick-diameter round steel is used at the bottom corner of the roadway to control the floor heave, the long anchor cable is added at the roadway intersection and the surrounding rock is reinforced by pre-grouting before the support at the local broken section or fault location.

\subsection{Field Experiments}

Based on the new support scheme, the in-site industrial experiments about roadway deformation monitoring are implemented in three months with SWJ-IV tunnel convergence gauge. Four different support plans have been designed to test the support performance. The test site is located on the $100 \mathrm{~m}$ region of 640 middle levels in the Kaiyang mine area.

As shown in Table 3, roadway deformation monitoring for different support plans starts simultaneously in different locations, but the displacement of roadway excavated a long time ago is still larger than the new excavated roadway that adopted the new support plan. The monitoring result has verified the superiority in new support designs, as shown in Figure 15. The new plan can sharply reduce the displacement of roadways. Especially, the sides' displacement declined from $50 \%$ and roof and floor displacement decreased about $78 \%$ in comparison to the original support. Plan I and IV with original support is excavated before plans II and III, and especially plan IV is excavated a long time ago. The 
roadway displacement of support plans II and III is obviously smaller than support plan I and IV's. The displacement of floor is predominant in parts with the displacement of vertical direction for four support plans. Meanwhile, the displacement of roadway of plan II in a horizontal direction and a vertical direction respectively declined about $78 \%$ and $50 \%$ in comparison to plan I and IV's so that improved roadway stability.

Table 3. The convergence deformation of different support plans in three months.

\begin{tabular}{cccc}
\hline $\begin{array}{c}\text { The Number of the } \\
\text { Support Plan }\end{array}$ & Support Method & Excavating Time & Floor Control \\
\hline Plan one & Original & Lately & New floor spraying \\
Plan two & $\mathrm{New}$ & Lately & Floor with metallic net \\
Plan three & $\mathrm{New}$ & Lately & New floor spraying \\
Plan four & Original & Early & Original floor \\
\hline
\end{tabular}

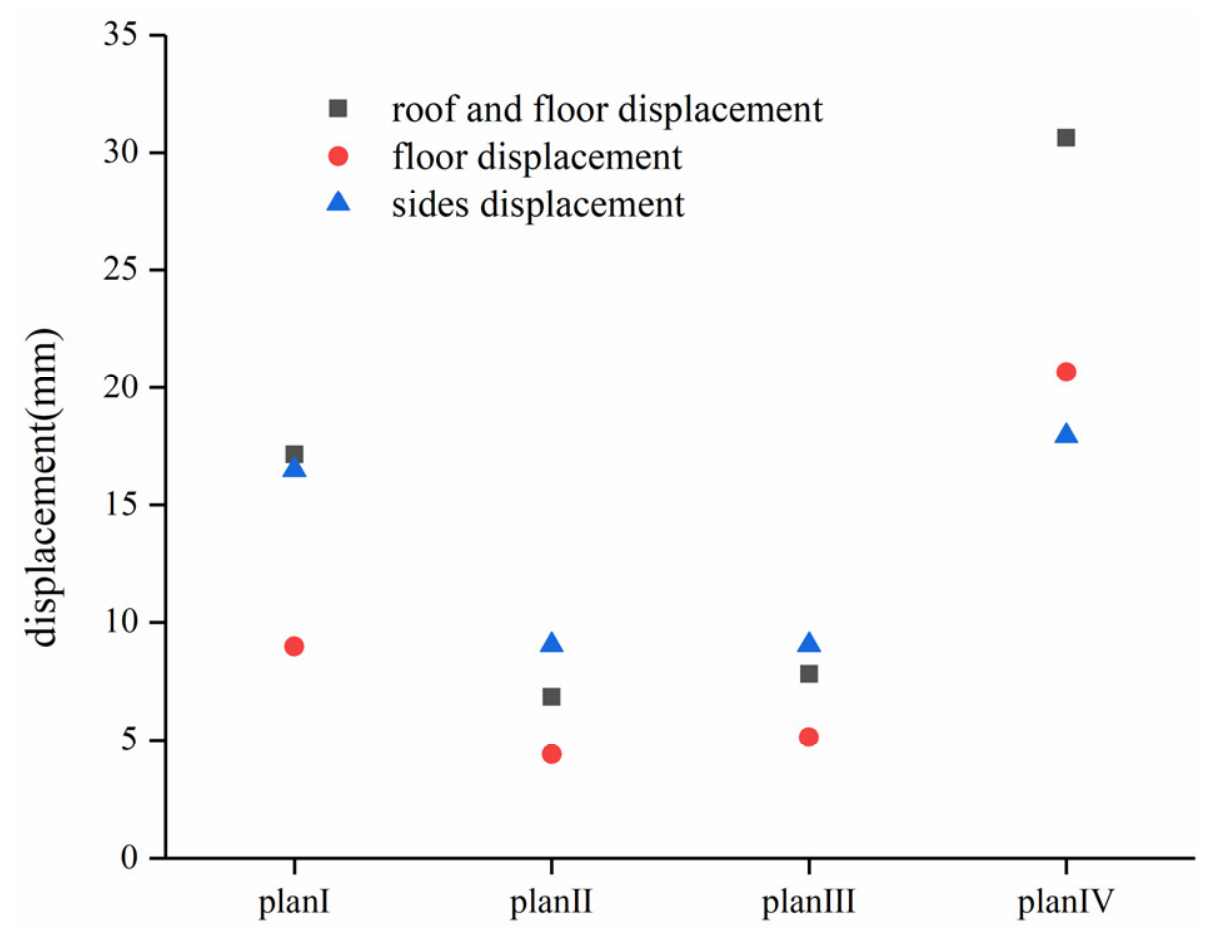

Figure 15. The new support scheme and support parameters.

Plan II has a good performance in control of roadway deformation. According to in-site observation in deformation monitoring experiment, the appearance and morphology of the roadway surface is smooth and straight and surrounding rock does not crack to failure and even to be slump block.

\section{Conclusions}

(1) According to the lab test of red shale, the mineral composition and microstructure, anisotropic and hydraulic mechanical properties of red shale have been investigated. According to laboratory experiments analysis and validation of numerical simulation, red shale deformation characteristics can be drawn as three deformation mechanisms of weathering collapse after water absorption, destruction under high stress and uniformed destruction distribution for bedding structure. The multi-reaction of water and rock mass leads to rock crack and collapse and bolt retraction to damage roadway stability, and the layered rock moves to destruction and local deformation on roof. Numerical simulation 
analysis has verified the deformation phenomenon in field. Also bedding structure is affected a lot under stress distribution.

(2) Based on deep analysis of compound failure mechanisms, the coupled support method is applied to transfer mechanisms. Then, the approved version of shotcrete rock bolt mesh technique was proposed to new-designed wave-type bolts layout. The wave-type bolts can relieve roadway supports loading and controlling excess deformation. The layout of wave-type bolts and regular bolts were used to adjust the uneven stress distribution and strengthen some parts' support. The installing angle of bolts is sufficiently considered in the influence of bedding orientations. Meanwhile, the shotcrete rock bolt mesh technique can guarantee enough support of rigidity and strength to relieve the uneven support loading on weak parts of roadway.

(3) The result of the study is applied to 640 levels in the Kaiyang mine area. Four support plans of in-site industrial experiments about roadway deformation monitoring are implemented in three months with SWJ-IV tunnel convergence gauge. The consequences have verified the new support design's superiority. Afterwards, the new support technologies have been applied to Kaiyang mine area and behave well.

Author Contributions: Writing-review and editing: C.M., J.X. and G.T.; Experimental test: W.X., Z.L.; Numerical simulation: G.T. All authors have read and agreed to the published version of the manuscript.

Funding: This research was funded by the Open Sharing Fund for the Large-scale Instruments and Equipments of Central South University (number CSUZC202133), National Natural Science Foundation of China (52074352).

Conflicts of Interest: The authors declare no conflict of interest.

\section{References}

1. Lin, P.; Li, S.C.; Xu, Z.H.; Wang, J.; Huang, X. Water Inflow Prediction during Heavy Rain While Tunneling through Karst Fissured Zones. Int. J. Géoméch. 2019, 19, 04019093. [CrossRef]

2. Chen, Y.; Meng, Q.; Xu, G.; Wu, H.; Zhang, G. Bolt-grouting combined support technology in deep soft rock roadway. Int. J. Min. Sci. Technol. 2016, 26, 777-785. [CrossRef]

3. Chen, X.; Guo, H.; Zhao, P.; Peng, X.; Wang, S. Numerical modeling of large deformation and nonlinear frictional contact of excavation boundary of deep soft rock tunnel. J. Rock Mech. Geotech. Eng. 2011, 3, 421-428. [CrossRef]

4. Cao, R.; Cao, P.; Lin, H. Support technology of deep roadway under high stress and its application. Int. J. Min. Sci. Technol. 2016, 26, 787-793. [CrossRef]

5. Shen, B. Coal Mine Roadway Stability in Soft Rock: A Case Study. Rock Mech. Rock Eng. 2014, 47, 2225-2238. [CrossRef]

6. He, M.; Xie, H.; Peng, S.; Jiang, Y. Study on rock mechanics in deep mining engineering. Chin. J. Rock Mech. Eng. 2005, 16, 2803-2813. (in Chinese).

7. Li, G.; Ma, F.; Guo, J.; Zhao, H.; Liu, G. Study on deformation failure mechanism and support technology of deep soft rock roadway. Eng. Geol. 2020, 264, 105262. [CrossRef]

8. Tian, $\mathrm{S} . ; \mathrm{Xu}, \mathrm{X} . ; \mathrm{Li}, \mathrm{Z}$. Disaster-inducing mechanism in a roadway roof near the driving face and its safety-control criteria. Saf. Sci. 2019, 115, 208-214. [CrossRef]

9. Yang, H.; Cao, S.; Li, Y.; Sun, C.; Guo, P. Soft Roof Failure Mechanism and Supporting Method for Gob-Side Entry Retaining. Minerals 2015, 5, 707-722. [CrossRef]

10. Kovačević, M.S.; Bačić, M.; Gavin, K.; Stipanović, I. Assessment of long-term deformation of a tunnel in soft rock by utilizing particle swarm optimized neural network. Tunn. Undergr. Space Technol. 2021, 110, 103838. [CrossRef]

11. Golser, J. The New Austrian Tunneling Method (NATM), Theoretical Background \& Practical Experiences. In Proceedings of the 2nd Shotcrete Conference, Easton, PA, USA, 4-8 October 1976.

12. Wu, L.; Cui, C.; Geng, N.; Wang, J. Remote sensing rock mechanics (RSRM) and associated experimental studies. Int. J. Rock Mech. Min. Sci. 2000, 37, 879-888. [CrossRef]

13. Li, Y.; Zhang, D.; Fang, Q.; Yu, Q.; Xia, L. A physical and numerical investigation of the failure mechanism of weak rocks surrounding tunnels. Comput. Geotech. 2014, 61, 292-307. [CrossRef]

14. He, M.; Gong, W.; Wang, J.; Qi, P.; Tao, Z.; Du, S.; Peng, Y. Development of a novel energy-absorbing bolt with extraordinarily large elongation and constant resistance. Int. J. Rock Mech. Min. Sci. 2014, 67, 29-42. [CrossRef]

15. Li, S.; Wang, Q.; Wang, H.; Jiang, B.; Wang, D.; Zhang, B.; Li, Y.; Ruan, G. Model test study on surrounding rock deformation and failure mechanisms of deep roadways with thick top coal. Tunn. Undergr. Space Technol. 2015, 47, 52-63. [CrossRef]

16. Yang, S.-Q.; Chen, M.; Jing, H.-W.; Chen, K.-F.; Meng, B. A case study on large deformation failure mechanism of deep soft rock roadway in Xin'An coal mine, China. Eng. Geol. 2017, 217, 89-101. [CrossRef] 
17. Guo, P.; He, M.; Wang, J. Study on Coupling Support Technique in the Roadway of Hecaogou No. 2 Coal Mine with Soft Roadway of Large Deformation. Geotech. Geol. Eng. 2017, 1-13. [CrossRef]

18. Wang, Q.; Jiang, B.; Pan, R.; Li, S.-C.; He, M.-C.; Sun, H.-B.; Qin, Q.; Yu, H.-C.; Luan, Y.-C. Failure mechanism of surrounding rock with high stress and confined concrete support system. Int. J. Rock Mech. Min. Sci. 2018, 102, 89-100. [CrossRef]

19. Meng, B.; Jing, H.; Chen, K.; Su, H. Failure mechanism and stability control of a large section of very soft roadway surrounding rock shear slip. Int. J. Min. Sci. Technol. 2013, 23, 127-134. [CrossRef]

20. Jia, P.; Tang, C. Numerical study on failure mechanism of tunnel in jointed rock mass. Tunn. Undergr. Space Technol. 2008, 23, 500-507. [CrossRef]

21. Wang, Z.; Wang, C.; Wang, X. Research on High Strength and Pre-stressed Coupling Support Technology in Deep Extremely Soft Rock Roadway. Geotech. Geol. Eng. 2018, 36, 3173-3182. [CrossRef]

22. Chang, Q.; Zhou, H.; Xie, Z.; Shen, S. Anchoring mechanism and application of hydraulic expansion bolts used in soft rock roadway floor heave control. Int. J. Min. Sci. Technol. 2013, 23, 323-328. [CrossRef]

23. Wang, Q.; Pan, R.; Jiang, B.; Li, S.; He, M.; Sun, H.; Wang, L.; Qin, Q.; Yu, H.; Luan, Y. Study on failure mechanism of roadway with soft rock in deep coal mine and confined concrete support system. Eng. Fail. Anal. 2017, 81, 155-177. [CrossRef]

24. Shreedharan, S.; Kulatilake, P.H.S.W. Discontinuum-Equivalent Continuum Analysis of the Stability of Tunnels in a Deep Coal Mine Using the Distinct Element Method. Rock Mech. Rock Eng. 2016, 49, 1903-1922. [CrossRef]

25. Yu, K.; Ren, F.; Puscasu, R.; Lin, P.; Meng, Q. Optimization of combined support in soft-rock roadway. Tunn. Undergr. Space Technol. 2020, 103, 103502. [CrossRef]

26. Qu, G.L.; Wang, J.; Liu, G.L. Research on Supporting Theory of Pressure-Bearing Ring and Yield Supporting Technology in Extremely Soft Rock Roadway. Appl. Mech. Mater. 2013, 395-396, 536-543. [CrossRef]

27. Ran, J.Q.; Passaris, E.K.S.; Mottahed, P. Shear sliding failure of the jointed roof in laminated rock mass. Rock Mech. Rock Eng. 1994, 27, 235-251. [CrossRef]

28. Wu, G.; Chen, W.; Jia, S.; Tan, X.; Zheng, P.; Tian, H.; Rong, C. Deformation characteristics of a roadway in steeply inclined formations and its improved support. Int. J. Rock Mech. Min. Sci. 2020, 130, 104324. [CrossRef]

29. Varden, R.; Lachenicht, R.; Player, J.; Thompson, A.; Villaescusa, E. Development and Implementation of the Garford Dynamic Bolt at the Kanowna Belle Mine. Australas. Inst. Mining Metall. Publ. Ser. 2008, 10, 95-102. 